\title{
GAMBARAN PENGETAHUAN MASYARAKAT TENTANG PENYAKIT MALARIA DI KECAMATAN SILIAN RAYA KABUPATEN MINAHASA TENGGARA
}

\author{
${ }^{1}$ Cecilia S.Akay \\ ${ }^{2}$ Josef S. B. Tuda \\ ${ }^{2}$ Victor D. Pijoh
${ }^{1}$ Kandidat Skripsi Bagian Fisika Kedokteran Universitas Sam Ratulangi Manado
${ }^{2}$ Bagian Parasitologi Fakultas Kedokteran Universitas Sam Ratulangi Manado
Email: c.akay11_019@yahoo.com

\begin{abstract}
Malaria is a disease caused by the protozoa obligate intracellular species of Plasmodium genus. In Indonesia, malaria is a very complex problem of public health. This was a descriptive study, using questionnaires to the respondents. The study was conducted in Silian Raya (Minahasa Tenggara) during October 2014 until January 2015. There were 194 respondents. Sampling system was based on cluster random sampling in each village, then for sampling of each village we used simple random sampling. All respondents had heard about malaria disease (100\%), and most respondents obtained that information from health counseling (65.5\%). The knowledge that malaria was due to mosquito bites were found among 99.5\% respondents, but most respondents did not know about the type of mosquitoes that caused malaria. The knowledge about the time that the mosquitoes transmitting malaria bit at night was found among $57.7 \%$ respondents. The knowledge about the breeding of malaria mosquito was found among 99.5\% respondents; about signs and symptoms of malaria $99.5 \%$ respondents; and prevention of malaria $99.5 \%$ respondents.
\end{abstract}

Keywords: malaria, knowledge

\begin{abstract}
Abstrak: Malaria adalah suatu penyakit yang disebabkan oleh protozoa obligat intraseluler dari genus Plasmodium. Di Indonesia penyakit malaria merupakan masalah kesehatan masyarakat yang multi kompleks. Jenis penelitian yang dilakukan adalah deskriptif, dengan melakukan komunikasi langsung berupa wawancara atau kuesioner kepada responden. Penelitian dilakukan di Kecamatan Silian Raya Kabupaten Minahasa Tenggara dan waktu penelitian di laksanakan selama bulan Oktober 2014 sampai Januari 2015 dengan responden sebanyak 194 orang dan pengambilan sampel berdasarkan sistem Cluster Random Sampling pada masing-masing desa, kemudian untuk pengambilan sampel setiap desa menggunakan Simple Random Sampling. Semua responden pernah mendengar tentang penyakit malaria (100\%)dan paling banyak responden mendengar informasi tersebut dari penyuluhan kesehatan (65.5\%). Untuk pengetahuan responden tentang gigitan penyebab penyakit malaria ialah oleh gigitan nyamuk (99,5\%), tetapi responden paling banyak tidak tahu (68\%) tentang jenis nyamuk penular penyebab penyakit malaria. Untuk Pengetahuan responden tentang waktu menggigit nyamuk penular penyebab penyakit malaria ialah malam hari (57.7\%). Pengetahuan responden tentang tempat perindukan nyamuk penyebab malaria(99,5\%),tanda dan gejala penyakit malaria(99,5\%), dan pencegahan penyakit malaria (99,5\%).
\end{abstract}

Kata kunci: malaria, pengetahuan

Malaria merupakan penyakit infeksi parasit yang penting di dunia. ${ }^{1}$ Menurut World
Malaria Report tahun 2012diperkirakan jumlah kasus malaria di duniasebanyak 207 
juta dan kematian yang diakibatkanmalaria sebanyak 627 ribu. $^{2}$ Penduduk dunia yang berisiko terkena penyakit malaria hampir setengah dari keseluruhan penduduk di dunia, terutama negara-negara berpenghasilan rendah. ${ }^{3}$

Di Indonesia penyakit malaria masih merupakan masalah kesehatan masyarakat yang multi kompleks, sebab dapat meningkatkan kematian pada bayi, anak di bawah lima tahun dan ibu melahirkan serta dapat menurunkan produktifitas kerja dan bahkan dapat menimbulkan gangguan dan menurunkan citra dan nilai politis suatu negara. Penyakit ini sebagian besar penderitanya berasal dari daerah pedesaan dan golongan ekonomi lemah. ${ }^{4}$

Menurut Survei Kesehatan Rumah Tangga (SKRT) tahun 2011, di Indonesia terdapat 15 juta kasus malaria dengan 38 ribu kematian setiap tahunnya. ${ }^{5}$ Tahun 2011 terdapat 374 kabupaten endemis malaria. ${ }^{2}$ Jumlah kasus malaria pada tahun 2006 sebanyak 2 juta kasus dan pada tahun 2007 menurun menjadi 1.774.845 kasus. ${ }^{3}$ Pada tahun 2011 sebanyak 256.592 kasus dari 1.322.451 kasus suspek malaria yang diperiksa sediaan darahnya. ${ }^{2}$ Walaupun kasus malaria menurun, tetapi menurut perhitungan para ahli berdasarkan teori ekonomi kesehatan dengan jumlah kasus malaria sebesar tersebut dapat menimbulkan kerugian ekonomi mencapai sekitar 3 triliun rupiah lebih. Kerugian tersebut sangat berpengaruh terhadap pendapatan daerah. ${ }^{6}$

Di Sulawesi Utara penyakit malaria termasuk dalam urutan atas dari sepuluh penyakit menonjol di puskesmas dan rumah sakit. $^{7}$ Tahun 2010 jumlah kasus malaria yang ada di Provinsi Sulawesi Utara mengalami peningkatan, dari Annual Parasite Incidence(API) sebesar 1,63 per 1000 penduduk naik menjadi 2,52 per 1000 penduduk pada tahun $2011{ }^{8}$

Kabupaten Minahasa Tenggara merupakan salah satu kabupaten/kota dengan jumlah kasus malaria yang tinggi. Tahun 2011 kasus malaria positif adalah 2001 kasus dan terjadi peningkatan kasus pada tahun 2012 menjadi 2005 positif malaria. Data kasus penyakit malaria yang ada di kabupaten Minahasa Tenggara menunjukkan tingginya angka kejadian malaria di Puskesmas Touluaan, tahun 2011 kasus malaria positif yaitu 574 dan naik pada tahun 2012 menjadi 962 yang positif malaria. ${ }^{8,9}$ Data kasus malaria di Puskesmas Silian Raya, tahun 2013 kasus malaria positif yaitu 317 dan pada tahun 2014 yaitu 159 yang positif malaria. ${ }^{10}$

Upaya pencegahan penularan penyakit malaria telah banyak dilakukan seperti "gebrak malaria” sebagai gerakan nasional memberantas malaria di Indonesia. Gerakan malaria ini belum mampu menanggulangi penyakit malaria, terutama di daerah endemis. ${ }^{11}$ Kasus kesakitan juga masih selalu ada karena masalah pencegahan (preventif) penularan belum cukup efektif mengeliminasi permasalahan secara tuntas. ${ }^{12}$ Pengetahuan masyarakat yang terbatas merupakan determinan penting bagi munculnya penyakit malaria, ${ }^{13}$ dan berpengaruh terhadap partisipasi masyarakat dalam program pencegahan penyakit malaria. $^{12}$

Tujuan umum penulisan ini untuk mendapatkan gambaran pengetahuan masyarakat tentang penyakit malaria di Kecamatan Silian Raya Kabupaten Minahasa Tenggara.

\section{METODE PENELITIAN}

Penelitian ini merupakan survei deskriptif. Penelitian dilakukan di Kecamatan Silian Raya Kabupaten Minahasa Tenggara Provinsi Sulawesi Utara pada bulan Oktober 2014 sampai Januari 2015.

Populasi penelitian ini yaitu seluruh penduduk Kecamatan Silian Raya Kabupaten Minahasa Tenggara dengan jumlah penduduk 5.731 jiwa atau 1.624 KK. Sampel adalah masyarakat yang bersedia mengikuti penelitian ini dan besar sampel dihitung berdasarkan rumus yang dikutip dari Notoadtmojo, maka besar sampel yang dibutuhkan berjumlah 98 orang. Jumlah sampel dibagi dalam 10 desa sebagai cluster dengan menggunakan sistem Cluster Random Sampling, 
kemudian untuk pengambilan sampel setiap desa menggunakan Simple Random Sampling. Dalam penelitian ini digunakan sampel sebesar 194 orang yang didapat dari masing-masing desa Kecamatan Silian Raya dengan kriteria kelompok usia 15-20 tahun, 20-30 tahun, dan lebih dari 30 tahun yang bersedia untuk di wawancara. Data yang digunakan terdiri dari data primer dan data sekunder. Data primer diperoleh dengan cara kunjungan ke rumah responden dengan menggunakan kuesioner dan metode wawancara. Data sekunder diperoleh dari literatur yang relevan dengan penelitian.

Data yang diteliti dikumpulkan secara manual kemudian dikomputerisasi dan disajikan dalam bentuk tabel distribusi frekuensi dan diuraikan dalam bentuk narasi.

\section{HASIL PENELITIAN}

\section{Gambaran umum lokasi penelitian}

Kecamatan Silian Raya merupakan lokasi penelitian yang telah dilakukan oleh peneliti yang terletak di Kabupaten Minahasa Tenggara Provinsi Sulawesi Utara. Luas Kecamatan Silian Raya adalah 4.083,86 hektar dalam koordinat 01,06388 LU dan 124,66615 BT dengan ketinggian $418 \mathrm{~m} .{ }^{14}$

Secara geografis letak wilayah Kecamatan Silian Raya berada di sebelah Selatan Kecamatan Tombatu, sebelah Barat berbatasan dengan Kecamatan Touluaan, sebelah Timur berbatasan dengan Kecamatan Tombatu Utara dan sebelah Utara berbatasan dengan Kabupaten Minahasa Selatan. ${ }^{14}$

Jumlah penduduk Kecamatan Silian Raya Kabupaten Minahasa Tenggara yaitu 5.731 jiwa atau $1.624 \mathrm{KK}$ yang terdiri dari 2.956 jiwa laki-laki dan 2.775 jiwa perempuan. ${ }^{14}$

\section{Karakteristik Responden}

Responden paling banyak dalam kelompok usia $>30$ tahun dan responden perempuan lebih banyak daripada laki-laki. Paling banyak responden tidak bekerja termasuk didalamnya IRT, pensiunan, dan pelajar sedangkan responden yang bekerja terbanyak yaitu sebagai petani. Untuk status pendidikan terbanyak responden merupakan tamatan Sekolah Menengah Pertama (SMP) dan paling sedikit tamatan Perguruan Tinggi.

Tabel 1. Karakteristik responden Pengetahua Masyarakat tentang Penyakit Malaria tahun 2015

\begin{tabular}{lcc}
\hline Karakteristik responden & $\mathrm{N}$ & $\%$ \\
\hline Usia Responden & & \\
$<20$ tahun & 6 & 3.1 \\
$20-30$ tahun & 42 & 21.6 \\
$>30$ tahun & 146 & 75.3 \\
\hline Jenis Kelamin & & \\
Laki-laki & 79 & 40.7 \\
Perempuan & 115 & 59.3 \\
\hline Pekerjaan & & \\
PNS/TNI/POLRI & 10 & 5.2 \\
Pegawai Swasta & 1 & 0.5 \\
Pedagang & 6 & 3.1 \\
Petani & 74 & 38.1 \\
Lain-lain (IRT, & 103 & 53.1 \\
Pensiun, Pelajar) & & \\
\hline Pendidikan & & \\
Tamat SD & 35 & 18.0 \\
Tamat SMP & 99 & 51.0 \\
Tamat SMA & 48 & 24.7 \\
Tamat Perguruan & 12 & 6.2 \\
Tinggi (DIII, S1,S2) & & \\
\hline
\end{tabular}

\section{Pengetahuan responden tentang penyakit malaria}

Tabel 2 memperlihatkan bahwa semua responden pernah mendengar tentang penyakit malaria dan paling banyak responden mendengar informasi tersebut dari penyuluhan kesehatan.

Tabel 3 menunjukkan bahwa responden paling banyak menjawab malaria disebabkan oleh gigitan nyamuk.

Tabel 4 menunjukkan bahwa responden paling banyak menjawab tidak tahu tentang jenis nyamuk penular penyebab penyakit malaria.

Tabel 5 memperlihatkan bahwa responden paling banyak menjawab nyamuk malaria menggigit pada waktu malam hari. 
Tabel 2. Responden yang pernah mendengar tentang penyakit malaria dan distribusi sumber informasi tentang penyakit malaria

\begin{tabular}{lcc}
\hline \multicolumn{1}{c}{ Kategori } & $\mathrm{N}$ & $\%$ \\
\hline \multicolumn{1}{c}{ Pernah } & 194 & 100,0 \\
Tidak Pernah & 0 & 0 \\
\hline \multicolumn{1}{c}{ Jumlah } & 194 & 100,0 \\
\hline TV/media elektronik & 24 & 12,4 \\
Koran & 4 & 2,1 \\
$\begin{array}{l}\text { Penyuluhan tentang } \\
\text { kesehatan }\end{array}$ & 127 & 65,5 \\
$\begin{array}{l}\text { Lain-lain (dari } \\
\text { masyarakat/keluarga, } \\
\text { pada saat sakit) }\end{array}$ & 39 & 20,1 \\
\hline \multicolumn{1}{c}{ Jumlah } & 194 & 100.0 \\
\hline
\end{tabular}

Tabel 3. Distribusi responden berdasarkan pengetahuan tentang gigitan penyebab penyakit malaria

\begin{tabular}{ccc}
\hline Gigitan & $\mathrm{N}$ & $\%$ \\
\hline Nyamuk & 193 & 99,5 \\
Anjing & 0 & 0 \\
Tikus & 0 & 0 \\
Lain-lain & 1 & 0,5 \\
(tidak tahu) & & \\
\hline Jumlah & 194 & 100.0 \\
\hline
\end{tabular}

Tabel 4. Distribusi responden berdasarkan pengetahuan tentang jenis nyamuk penular penyebab penyakit malaria

\begin{tabular}{ccc}
\hline Jenis nyamuk & $\mathrm{N}$ & $\%$ \\
\hline Anopheles & 38 & 19,6 \\
Culex & 4 & 2,1 \\
Aedes aegypty & 20 & 10,3 \\
Tidak tahu & 132 & 68,0 \\
\hline Jumlah & 194 & 100,0 \\
\hline
\end{tabular}

Tabel 5. Distribusi responden berdasarkan pengetahuan tentang waktu menggigit nyamuk penular penyebab penyakit malaria

\begin{tabular}{ccc}
\hline Waktu & $\mathrm{N}$ & $\%$ \\
\hline Pagi & 11 & 5.7 \\
Siang & 71 & 36.6 \\
Malam & 112 & 57.7 \\
\hline Jumlah & 194 & 100.0 \\
\hline
\end{tabular}

Tabel 6 menunjukkan bahwa responden yang tahu lebih banyak daripada yang tidak tahu tentang tempat perindukan nyamuk penyebab malaria. Responden lebih banyak menjawab benar daripada salah terhadap beberapa pilihan tempat perindukan nyamuk penyebab malaria.

Tabel 6. Distribusi responden berdasarkan pengetahuan tentang tempat perindukan nyamuk penyebab malaria

\begin{tabular}{|c|c|c|c|c|}
\hline Kategori & & $\mathrm{N}$ & & $\%$ \\
\hline Tahu & & 193 & & 9,5 \\
\hline Tidak tahu & & 1 & & 0,5 \\
\hline Jumlah & & 194 & & 00,0 \\
\hline \multirow{2}{*}{$\begin{array}{c}\text { Tempat } \\
\text { perindukan }\end{array}$} & \multicolumn{2}{|c|}{ Benar } & \multicolumn{2}{|c|}{ Salah } \\
\hline & $\mathrm{N}$ & $\%$ & $\mathrm{~N}$ & $\%$ \\
\hline Rawa & 184 & 94,8 & 9 & 4,6 \\
\hline Sawah & 162 & 83,5 & 31 & 16,0 \\
\hline Kolam & 166 & 85,6 & 27 & 13,9 \\
\hline $\begin{array}{l}\text { Genangan } \\
\text { air }\end{array}$ & 190 & 97,9 & 3 & 1,5 \\
\hline
\end{tabular}

Tabel 7 menunjukkan bahwa responden yagn tahu lebih banyak daripada yang tidak tahu tentang tanda dan gejala penyakit malaria dan lebih banyak responden yang menjawab benar daripada salah terhadap beberapa pilihan tanda dan gejala penyakit malaria.

Tabel 7. Distribusi responden berdasarkan pengetahuan tentang tanda dan gejala penyakit malaria

\begin{tabular}{ccc}
\hline Kategori & $\mathrm{N}$ & $\%$ \\
\hline Tahu & 193 & 99,5 \\
Tidak tahu & 1 & 0,5 \\
\hline Jumlah & 194 & 100,0 \\
\hline
\end{tabular}

\begin{tabular}{lcccc}
\multirow{2}{*}{$\begin{array}{c}\text { Tanda dan } \\
\text { gejala }\end{array}$} & \multicolumn{2}{c}{ Benar } & \multicolumn{2}{c}{ Salah } \\
\cline { 2 - 5 } & $\mathrm{N}$ & $\%$ & $\mathrm{~N}$ & $\%$ \\
\hline Panas & 192 & 99,0 & 1 & 0,5 \\
menggigil & & & & \\
Sakit kepala & 191 & 98,5 & 2 & 1,0 \\
$\begin{array}{l}\text { Mual } \\
\text { muntah }\end{array}$ & 178 & 91,8 & 15 & 7,7 \\
Lemas pucat & 184 & 94,8 & 9 & 4,6 \\
\hline
\end{tabular}


Tabel 8. Distribusi responden berdasarkan pengetahuan tentang pencegahan penyakit malaria

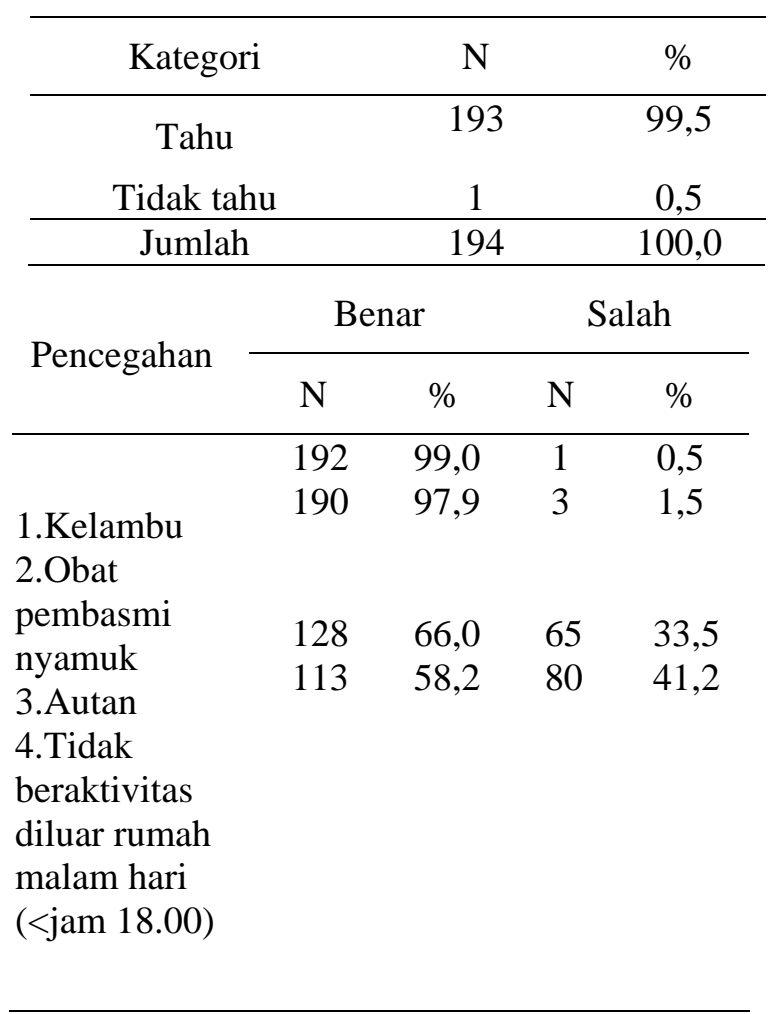

Tabel 8 menunjukkan bahwa responden lebih banyak tahu daripada tidak tahu tentang pencegahan penyakit malaria. Kemudian responden lebih banyak menjawab benar daripada salah terhadap beberapa pilihan pencegahan penyakit malaria.

\section{BAHASAN}

\section{Karakteristik Responden}

Dari hasil penelitian, usia terbanyak yang bersedia di wawancarai melalui kuesioner yaitu lebih dari 30 tahun dan responden terbanyak adalah perempuan. Hal ini karena sebagian besar perempuan yang berada di dalam rumah saat di wawancarai dan tidak bekerja atau sebagai ibu rumah tangga.

Dari hasil penelitian tentang status pekerjaan responden dibandingkan dengan hasil penelitian oleh Manalu dan Sukowati (2011) di Kota Batam yaitu pekerjaan utama responden terbanyak sebagai wiraswasta atau berdagang buka warung di rumah. $^{6}$

Pada penelitian ini tingkat pendidikan responden dibandingkan dengan hasil penelitian oleh Ma'ruf (2014) di desa Tunggulo Kecamatan Limboto Barat Kabupaten Gorontalo yaitu sebagian besar pendidikan terakhir ialah SD. ${ }^{15}$

\section{Gambaran pengetahuan responden tentang penyakit malaria}

Dari hasil penelitian responden yang pernah mendengar tentang penyakit malaria dibandingkan dengan hasil penelitian oleh Juhairiyah dan kawan-kawan (2014) di Kabupaten Malinau Propinsi Kalimantan Timur mendapat persentase $67,2 \% .^{2}$ Di Desa Tatelu Kecamatan Dimembe oleh Taufik dan kawan-kawan (2013) juga mendapat hasil penelitian dengan presentase $75 \%{ }^{5}$

Dari hasil penelitian sumber informasi tentang penyakit malaria dibandingkan dengan hasil penelitian Taufik dan kawankawan sebagian besar tidak pernah mendapat penyuluhan malaria. ${ }^{5}$ Hal ini menunjukkan bahwa sumber informasi dari penyuluhan kesehatan mempengaruhi pengenalan tentang penyakit malaria pada masyarakat.

Dari hasil penelitian pengetahuan responden tentang gigitan penyebab penyakit malaria lebih baik dibandingkan dengan hasil penelitian Juhairiyah dan kawan-kawan responden yang menjawab seseorang tertular malaria melalui nyamuk hanya 37,3\%. ${ }^{2}$ Responden dari hasil penelitian Taufik dan kawan-kawan sebagian besar tidak tahu bahwa malaria ditularkan melalui gigitan nyamuk. ${ }^{5}$

Dari hasil penelitian pengetahuan responden tentang jenis nyamuk penular penyebab penyakit malaria masih kurang dan hanya sedikit yang dapat menjawab Anopheles.

Dari hasil penelitian pengetahuan responden tentang waktu menggigit nyamuk penular penyebab malaria dibandingkan hasil penelitian oleh Ngambut dan Sila (2013) di peroleh responden terbanyak menjawab waktu malam hari sebesar 47,1\% dan 37,1\% 
mengatakan nyamuk menggigit pada sore hari. ${ }^{16}$

Dari hasil penelitian pengetahuan responden tentang tempat perindukan nyamuk penyebab malaria dalam presentase 99,5\%. Tempat perindukan nyamuk sangat penting untuk diketahui sebagai bahan pengetahuan masyarakat dan manipulasi lingkungan guna upaya pencegahan malaria (DEPKES RI 1999). ${ }^{17}$

Dari hasil penelitian pengetahuan responden tentang tanda dan gejala penyakit malaria lebih baik dibandingkan responden hasil penelitian (Taufik Randy, 2013) sebagian besar menjawab tidak tahu. ${ }^{5}$ Tanda dan gejala penyakit malaria penting untuk diketahui, sebab dengan mengenal hal tersebut dapat cepat dilakukan tindakan lanjutan untuk pengobatan terhadap penyakit malaria. ${ }^{17}$

Dari hasil penelitian pengetahuan responden tentang pencegahan penyakit malaria dibandingkan hasil penelitian Taufik Randy (2013) sebagian besar yang tidak tahu penggunaan kelambu mencegah malaria yaitu $70 \%$ sedangkan yang mengetahui $30 \%$ dari persentase responden. ${ }^{5}$ Pengetahuan tentang usaha pencegahan penting untuk diketahui, sebab hal tersebut dapat menunjang untuk dilakukan tindakan pencegahan yang baik, dengan demikan dapat mengurangi populasi nyamuk malaria. ${ }^{17}$

\section{SIMPULAN}

Berdasarkan penelitian yang telah dilaksanakan di Kecamatan Silian Raya Kabupaten Minahasa Tenggara, dapat disimpulkan sebagai berikut

1. Sebagian besar responden berada pada kelompok usia $>30$ tahun dengan responden terbanyak perempuan, sehingga status pekerjaaan responden paling banyak yaitu tidak bekerja termasuk di dalamnya Ibu Rumah Tangga.Tingkat pendidikan responden sampai tamat Sekolah Menengah Pertama (SMP).

2. Semua responden pernah mendengar tentang penyakit malaria dan sebagian besar responden mendengar informasi tentang penyakit malaria dari penyuluhan kesehatan.

3. Sebagian besar masyarakat Kecamatan Silian Raya Kabupaten Minahasa Tenggara memiliki pengetahuan tentang gigitan penyebab penyakit malaria.

4. Sebagiankecil masyarakat Kecamatan Silian Raya Kabupaten Minahasa Tenggara memiliki pengetahuan tentang jenis nyamuk penular penyebab penyakit malaria.

5. Masyarakat Kecamatan Silian Raya Kabupaten Minahasa Tenggara memiliki pengetahuan tentang waktu menggigit nyamuk penular penyebab malaria sebesar $57.7 \%$.

6. Masyarakat Kecamatan Silian Raya Kabupaten Kabupaten Minahasa Tenggara memiliki pengetahuan tentang tempat perindukan nyamuk penyebab malaria sebesar 99,5\%.

7. Masyarakat Kecamatan Silian Raya Kabupaten Minahasa Tenggara memiliki pengetahuan tentang tentang tanda dan gejala penyakit malaria sebesar 99,5\%.

8. Masyarakat Kecamatan Silian Raya Kabupaten Minahasa Tenggara memiliki pengetahuan tentang tentang pencegahan penyakit malaria sebesar $99,5 \%$.

\section{SARAN}

Saran yang dapat disampaikan oleh peneliti dari hasil penelitian ini adalah sebagai berikut :

1. Bagi masyarakat Kecamatan Silian Raya Kabupaten Minahasa Tenggara untuk terus mencari tahu tentang penyakit malaria dengan harapan agar masyarakat dapat mencegah penyakit malaria.

2. Bagi Puskesmas Silian Raya dalam melaksanakan penyuluhan perlu lebih memberikan penjelasan terhadap masyarakat tentang penyakit malaria khususnya tentang jenis nyamuk penular penyebab penyakit malaria.

3. Bagi Dinas Kesehatan Provinsi Sulawesi Utara perlu dilakukan 
pelatihan-pelatihan khusus secara berkala untuk meningkatkan pengetahuan serta keterampilan kader kesehatan yang ada di Kecamatan Silian Raya Minahasa Tenggara.

4. Perlu dilakukan penelitian lanjutan untuk memantau tingkat pengetahuan masyarakat tentang penyakit malaria.

\section{DAFTAR PUSTAKA}

1. Tapan E. Flu, HFMD, Diare pada Pelancong, Malaria, Demam Berdarah, Tifus. Jakarta: Pustaka Populer Obor; 2004.h:100-106.

2. Juhairiyah. Pengetahuan dan perilaku masyarakat terhadap malaria di Kabupaten Melinau Propinsi Kalimantan Timur.Jurnal BUSKI.2014.

3. Hasibuan SA, Syahrial E, Keloko AB. Hubungan Karakteristik dengan Tindakan Ibu Rumah Tangga dalam Pencegahan Penyakit Malaria di desa Sorik Kecamatan Batang Angkola Kabupaten Tapanuli Selatan. Program Sarjana. Sumatera Utara: FKM USU Departemen Pendidikan Kesehatan dan Ilmu Perilaku; 2012.

4. Ningsi, Jastal, Maksud M. Studi Pengetahuan, Sikap dan Perilaku Penderita Malaria pada Daerah Perkebunan Coklat di Desa Malino Kec Marawola Kab Donggala. Jurnal vektor penyakit. 2009; 3(1): 31-32

5. Randy $T$, Ottay $R$, Palandeng $H$. Gambaran pengetahuan masyarakat tentang pencegahan penyakit malaria di desa Tatelu Kecamatan Dimembe. Jurnal. Manado: IKKom FK UNSRAT; 2013.

6. Manalu P, Sukowati S. Pengetahuan, Sikap dan Perilaku Masyarakat terhadap Malaria di Kota Batam. Artikel. Media Litbang Kesehatan;2011.

7. Purwanto D, Ottay R. Profil penyakit malaria pada penderita rawat inap di rumah sakit umum daerah kota bitung. Jurnal biomedik; 2011.avaible from: URL: http://download.portalgaruda.org/articl e.php?article $=16383 \&$ val $=1036 \&$ title

8. Asa PE, Umboh JML, Pangemanan J. Pengaruh Penggunaan Kelambu, Repelent, Bahan Anti Nyamuk dan Kebiasaan Keluar Rumah Malam Hari terhadap Kejadian Malaria di Desa Lobu dan Lobu II Kecamatan Touluaan Kabupaten Minahasa Tenggara. Manado: Fakultas Kesehatan Masyarakat Universitas Sam Ratulangi; 2013.

9. Dinkes (Minahasa Tenggara). Laporan Bulanan Penemuan dan Pengobatan Penderita Malaria. Dinas Kesehatan Kabupaten Minahasa Tenggara; 2012.

10.Data Puskesmas Kecamatan Silian Raya Kabupaten Minahasa Tenggara. 2014.

11.Depkes RI. Modul Promosi Gebrak Malaria. Jakarta: Ditjen PPM PLP; 2003.

12.Daulay RHD. Model Pengendalian Malaria Melalui Pendekatan Faktor Perilaku dan Lingkungan di Kecamatan Penyabungan Kota Kabupaten Mandailing Natal Propinsi Sumatera Utara. Tesis Pascasarjana Universitas Sumatera Utara, Medan; 2006.

13.Arsin A. Malaria di Indonesia Tinjauan Aspek Epidemiologi. Makasar: Masagena Press; 2012.

14.Data Administrasi Kecamatan Silian Raya Kabupaten Minahasa Tenggara.2014

15.Ma'Ruf A. Gambaran Perilaku Masyarakat tentang Penyakit Malaria di Desa Tunggulo Kecamatan Limboto Barat Kabupaten Gorontalo. Tesis. Gorontalo: Universitas Negeri Gorontalo, 2014

16.Ngambut K, Sila O. Faktor lingkungan dan Perilaku masyarakat tentang malaria di Kecamatan Kupang Timur Kabupaten Kupang. Jurnal Kesehatan Nasional. 2013.

17.Karundeng R. Gambaran Pengetahuan dan Tindakan Pencegahan Penyakit Malaria di Desa Tateli Jaga I Kecamatan Mandolang Kabupaten Minahasa Induk. Skripsi. Manado: FK Unsrat;2013. 